\title{
Combined galanin with insulin improves insulin sensitivity of diabetic rat muscles
}

\author{
Le Bu, Qian Yao', Zhimin Liư ${ }^{2}$, Wei Tang ${ }^{2}$, Junjie Zou' and Shen Qu
}

Department of Endocrinology, Shanghai 10th People's Hospital, Tongji University School of Medicine, 301 Yanchang Road, Shanghai 200072, China

${ }^{1}$ Key Laboratory of Sichuan Province of Medicinal Chemistry, Chengdu University, Chengdu 610106, China

${ }^{2}$ Department of Endocrinology, Changzheng Hospital, Second Military Medical University, Shanghai 200003, China
Correspondence should be addressed

to $\mathrm{S} Q u$

Email

lebu2000@sina.cn

\begin{abstract}
Although administration of galanin or insulin alone may enhance insulin sensitivity and glucose transporter 4 (GLUT4) trafficking, their cooperative effect on insulin sensitivity is still unclear. In the present study, we evaluated the cooperative effect of both reagents compared with solitary treatment with galanin or insulin in type 2 diabetic rats. Galanin and/or insulin were injected singly or together into type 2 diabetic rats once a day for 15 days. The results indicated that coadministration of both reagents compared with treatment with galanin or insulin alone significantly increased glucose infusion rates in euglycemichyperinsulinemic clamp tests, 2-deoxy-[ $\left.{ }^{3} \mathrm{H}\right] \mathrm{D}$-glucose contents, GLUT4 densities, and pAS160 and protein kinase $C$ activity levels, but reduced blood glucose and insulin levels, as well as retinol-binding protein 4 contents, and did not affect Glut4 (S/c2a4) mRNA expression levels in myocytes. The changes in the ratios of GLUT4 immunoreaction in plasma membranes to total cell membranes of myocytes were higher in the coadministrative group compared with either the insulin or the galanin group. These results indicate that cooperation of the two hormones plays a synergic role to improve GLUT4 translocation and insulin sensitivity. This finding indicates the possibility of combining galanin with insulin with the aim of obtaining better antidiabetic efficacy than that of the canonical treatment with insulin alone.
\end{abstract}

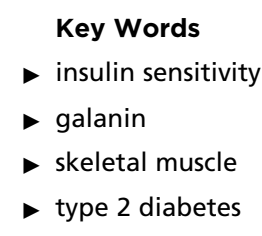

Journal of Endocrinology (2014) 221, 157-165

\section{Introduction}

Type 2 diabetes mellitus (T2DM) is a metabolic disorder characterized by hyperglycemia with insulin resistance, followed by $\beta$-cell failure. Traditional therapies centered around the concept of insulin and $\beta$-cells for the patients with this disease have only limited success. Reorientation in our understanding of 'insulin and islet pathology' should help rethink strategies that would yield better dividends in terms of effective therapy.

It has been clearly established that the neuropeptide galanin, initially isolated from the upper small intestine of the pig, is abundantly expressed in the digestive system, the
CNS and the peripheral nervous system (Jiang et al. 2009). As a versatile regulator, this peptide may ameliorate insulin resistance via boosting glucose transporter 4 (GLUT4) translocation, leading to glucose uptake into adipose and muscle tissues (Guo et al. 2011, He et al. 2011). Recent studies have provided compelling clues about the relationship between galanin and insulin sensitivity. First, high levels of galanin receptors are found in the skeletal muscle and adipose tissue of rats ( $\mathrm{Li}$ et al. 2004), i.e. the key sites involved in regulating glucose disposal and insulin sensitivity. Second, diabetic rats have an obvious reduction 
in plasma galanin levels and galanin-immunoreactive cell numbers in pancreatic islets compared with nondiabetic rats (Adeghate \& Ponery 2001). And animals with galanin metabolic disorder easily suffer from T2DM (Legakis 2005). Third, during an oral glucose tolerance test, the galanin concentration in healthy volunteers was positively correlated with blood glucose levels, exhibited a significant increase from time 0 to $90 \mathrm{~min}$, and returned to the basal values at $180 \mathrm{~min}$ (Legakis et al. 2007). Fourth, galaninknockout mice experienced impaired glucose disposal resulting from a reduction in insulin response and insulin-independent glucose elimination during the glucose tolerance tests (Ahrén et al. 2004), while the homozygous galanin transgenic C57BL/6J mice with the obese phenotype showed reduced energy expenditure and enhanced insulin sensitivity (Poritsanos et al. 2009). Finally, administration of M35, a galanin antagonist, reduced Glut4 (Slc2a4) mRNA and GLUT4 protein expression levels in the plasma membranes of myocytes and adipocytes, as well as glucose infusion rates in a hyperinsulinemic-euglycemic clamp test, which was a direct assessment of insulin sensitivity in subjects (Guo et al. 2011, Liang et al. 2012). These results indicate that galanin is an important hormone for elevating insulin sensitivity and glucose uptake, and that T2DM results from impairment of the functions of both galanin and insulin in the regulation of blood glucose homeostasis. Thus, the question is inferentially raised as to whether coadministration of galanin with insulin could have much better efficacy against T2DM than traditional insulin therapy alone.

To date, there are few results addressing the coadministrative role of both reagents in the treatment of T2DM. The current experiments were designed to estimate the cooperative effect of galanin and insulin on insulin sensitivity in the muscle tissues of the rats with T2DM.

\section{Materials and methods}

\section{Materials}

Trizol reagent was purchased from Gibco Invitrogen. Streptozotocin, galanin, and 2-deoxy- $\left[{ }^{3} \mathrm{H}\right] \mathrm{D}$-glucose $\left({ }^{3} \mathrm{H}-2 \mathrm{DG}\right)$ from Sigma-Aldrich, Inc. The PrimeScript reverse-transcribed reagent kit from Bioneer, Daejeon, South Korea. The protein kinase C (PKC) activity kit from Promega Corporation. The insulin ELISA kit from Mercodia, Uppsala, Sweden. GLUT4 and pAS160 antibodies from Santa Cruz Biotechnology, Inc. Rat retinol-binding protein 4 (RBP4) ELISA kit and secondary anti-rabbit antibody was obtained from Uscn Life Science, Inc., Wuhan, China. Insulin glargine was purchased from Ganli Pharmaceutical Co., Beijing, China.

\section{Animals and grouping}

Male Wistar rats $(150 \pm 10 \mathrm{~g})$ supplied by the Animal Center of Tongji University were acclimatized at $21 \pm 2{ }^{\circ} \mathrm{C}$, relative humidity $50 \pm 15 \%$, with a $12 \mathrm{~h}$ light: $12 \mathrm{~h}$ darkness cycle, fed with a high-fat diet (59\% fat, $21 \%$ protein and $20 \%$ carbohydrate), and water and allowed to eat and drink ad libitum. Each cage contained four rats. At the end of 8 weeks, rats were treated with $30 \mathrm{mg} / \mathrm{kg}$ streptozocin administered intraperitoneally (Atalik et al. 2010). After another 4 weeks, rats with fasting blood glucose level over $11.1 \mathrm{mmol} / \mathrm{l}$ with the symptoms of diuresis, positive glycosuria, and weight loss were classified as T2DM models. The experiments were carried out during the light phase of the cycle (0900-1100 h).

The 64 model rats were randomly divided into four groups: diabetic control, diabetic group with galanin, diabetic group with insulin, and diabetic group with galanin and insulin. In addition, a health control group was set up. Every group was composed of 16 members.

The rats in the three drug-treated groups were treated with galanin $(1 \mathrm{nmol} / \mathrm{kg}$, i.v. injection), insulin glargine (2 U/kg, s.c. injection), or both once a day for 15 successive days. The rats in both control groups were administered saline vehicle at same time. All animal procedures used were performed in accordance to the Guiding Principles for Care and the experiment was approved by the Tongji University Ethics Committee.

\section{Hyperinsulinemic-euglycemic clamp and 2DG tests}

At $6 \mathrm{~h}$ after the last injection, half of the rats in each group $(n=8)$ were anesthetized using an i.p. injection of $3 \%$ amobarbital sodium $(50 \mathrm{mg} / \mathrm{kg})$ individualized to each subject's body weight and subjected to hyperglycemic clamp tests, as previously described (Guo et al. 2011). Insulin at a constant rate of $2 \mathrm{mU} / \mathrm{kg}$ per min was infused through a catheter into the jugular vein until the end of the test. And $10 \%$ glucose was infused at variable rates as needed to clamp glucose levels at $5 \pm 0.5 \mathrm{mmol} / \mathrm{l}$. The glucose infusion rate was calculated corresponding to the last six samplings at the stable clamp level.

The other half of the rats in each group $(n=8)$ were fasted for $24 \mathrm{~h}$ after the 15-day treatment and then received intraperitoneal injections of $250 \mathrm{mg} / \mathrm{kg}{ }^{3} \mathrm{H}-2 \mathrm{DG}$ for $20 \mathrm{~min}$ in the $2 \mathrm{DG}$ tests. The quadriceps femoris and

Published by Bioscientifica Ltd. 
$4 \mathrm{ml}$ artery blood in the 2DG-treated rats were rapidly collected and stored at $-80^{\circ} \mathrm{C}$ until further analysis.

\section{Real-time PCR}

Quantitative PCR was carried out as described previously (He et al. 2011). Total RNA was isolated from $100 \mathrm{mg}$ muscle tissue using Trizol. The RNA concentration was measured at 260/280 $\mathrm{nm}$. cDNA was synthesized using the reverse-transcribed Premix kit as described by the manufacturer. $\beta$-actin was used as an internal reference and the mRNA expression of target genes was shown relative to $\beta$-actin. Real-time PCR was carried out using a quantitative PCR detection system (ExicyclerTM 96 PCR kit, LG Company, Seoul, Korea) under the following conditions: $95^{\circ} \mathrm{C} \times 10 \mathrm{~min}, 40 \times\left(95^{\circ} \mathrm{C} \times 30 \mathrm{~s}, 95^{\circ} \mathrm{C} \times 15 \mathrm{~s}, 62^{\circ} \mathrm{C} \times\right.$ 60 s). The specific Glut4 primers were as follows: forward 5'-ACAGGGCAAGGATGGTAGA-3', reverse 5'-TGGAGGGGAACAAGAAAGT- $3^{\prime}$. The $\beta$-actin primers were: forward 5'-GGCTGTGTTGTCCCTGTATG-3', reverse 5'-AATGTCACGCACGATTTCC- $3^{\prime}$. The $\Delta C \mathrm{t}$ value used to plot the relative gene level was calculated using the expression $2^{-\Delta \Delta C t}$.

\section{Isolation of plasma membrane of myocytes}

Muscle homogenates were separated by sucrose-gradient centrifugation as described previously (Jiang et al. 2009). Briefly, $12 \mathrm{~g}$ of skeletal muscle was minced and homogenized in cold buffer. The homogenate was then centrifuged at $1200 \mathrm{~g}$ for $10 \mathrm{~min}$ at $4{ }^{\circ} \mathrm{C}$. Part of the resulting supernatant was used for the measurement of pAS160 contents or ${ }^{3} \mathrm{H}-2 \mathrm{DG}$ uptake using a liquid scintillation counting (Tri-Carb 2000, Packard Instrument Co. Meriden, CT, USA), and the remains was centrifuged again at $8000 \boldsymbol{g}$ for $10 \mathrm{~min}$. A sample of the supernatant was used to determine PKC activity using an ELISA kit. The remainder was layered on a $25 \%$ and $50 \%$ sucrose gradient and centrifuged at $210000 \boldsymbol{g}$ for $2 \mathrm{~h}$ with L7-55UI ultracentrifuge (Beckman, Indianapolis, IN, USA).

\section{Measurement of PKC activity, plasma RBP4, and insulin levels}

PKC activity was measured using crude membrane preparations with the nonradioactive PKC activity kit according to the manufacturer's instructions.

Plasma samples were obtained through centrifugation at $210000 \boldsymbol{g}$ for $2 \mathrm{~h}$ at $4{ }^{\circ} \mathrm{C}$. Plasma insulin level was determined following a standard protocol with an ultrasensitive Insulin ELISA kit. The RBP4 contents were quantified using the competitive RBP4 ELISA kit with an intra-assay coefficient of variation (CV) of $5 \%$ and interassay $\mathrm{CV}$ of $9.7-9.8 \%$.

\section{Western blot analysis}

The samples $(50 \mu \mathrm{g})$ from the subcellular fractions were separated by $12 \%$ SDS-PAGE and transferred to a nitrocellulose membrane (Zhang et al. 2012). Then the membranes were immunoblotted with a primary antibody against GLUT4 or pAS160 C-terminal peptide and a HRP-conjugated secondary antibody successively. The blotted bands were visualized by chemiluminescence and quantified by densitometry with a HPIAS-2000 Image Analysis System.

\section{Statistical analysis}

For statistical comparison among groups, a $2 \times 2$ ANOVA followed by Tukey's test was employed. Data are reported as mean \pm s.E.M. Significance was accepted at $P<0.05$.

\section{Results}

\section{Body weight, blood glucose, and insulin levels}

The effects of coadministration of galanin and insulin vs each agent on body weight, blood glucose, and insulin levels in T2DM are shown in Fig. $1(F(4,40)=8.6, P<0.0001$; $F(4,40)=42.9, \quad P<0.0001 ; F(4,40)=24.1, P<0.0001)$. Compared with the galanin-only and insulin-only groups, the body weight in the coadministrative group was decreased by $1.5 \%(P>0.05)$ and increased by $3.3 \%(P>0.05)$ respectively; the blood glucose and insulin levels were decreased by $40.4 \%(P<0.01)$ and $19.2 \%(P<0.05)$ and $29.4 \%(P<0.05)$ and $39.3 \%(P<0.01)$ respectively. The body weight, blood glucose and insulin levels in the galanin-only and insulinonly groups compared with the diabetic controls were increased by $21.2 \%(P<0.01)$ and $15.4 \%(P<0.05)$, and reduced by $16.1 \%(P<0.05)$ and $38.1 \%(P<0.01), 33.3 \%$ $(P<0.01)$ and $22.5 \%(P<0.05)$, respectively. In the diabetic control group these indices were reduced by $18.8 \%(P<0.01)$, and elevated by $118.0 \%(P<0.01)$ and $139.6 \%(P<0.01)$ respectively compared with the normal controls.

\section{Hyperinsulinemic-euglycemic clamping}

Cotreatment with galanin and insulin obviously increased the glucose infusion rate during the clamp tests as shown in Fig. $2(F(4,40)=40.97, P<0.001)$. The infusive rate in coadiministrative group was increased by $29.6 \%(P<0.01)$ and

Published by Bioscientifica Ltd. 


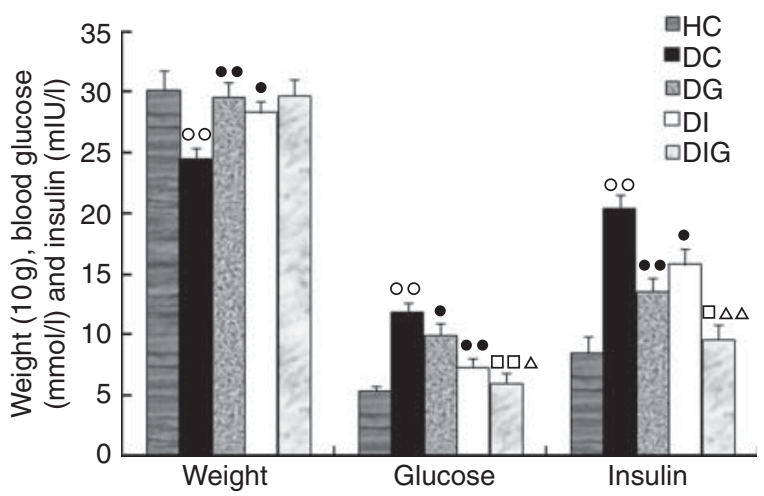

Figure 1

The effects of coadministration of galanin with insulin vs each agent alone on body weight, blood glucose, and insulin levels in type 2 diabetic rats $(n=8)$. The body weight of the rats in the coadministrative group (DIG) compared with either the galanin-only (DG) or the insulin-only group (DI) was almost unchanged, but the blood glucose and insulin levels were reduced. The body weight of the rats in the DG and DI groups was higher than that of animals in the diabetic control (DC) group, but the blood glucose and insulin levels were lower. Compared with the healthy control (HC) group, the body weight in the DC group was lower, but the blood glucose and insulin levels were higher. All data shown are the means \pm s.E.M. $\circ{ }_{P}<0.01$ vs HC; $\bullet P<0.05, \bullet \bullet<0.01$ vs DC; $\square P<0.05, \square \square P<0.01$ vs DG; $\triangle P<0.05, \triangle \triangle P<0.01$ vs DI.

24.4\% $(P<0.05)$ compared with the galanin- and insulintreated group respectively. The rate was increased by $40.8 \%$ $(P<0.05)$ and $45.6 \%(P<0.01)$ in the galanin- and insulintreated groups when compared with the diabetic control group, respectively. The infusion rates in the diabetic control group were significantly lower than those for the healthy control group $(P<0.01)$.

\section{Measurement of 2DG contents}

In this study, simultaneous injection of galanin and insulin significantly augmented the 2DG contents in the myocytes of diabetic rats $(F(4,40)=25.1, P<0.0001)$. The contents after coadministration of both reagents were enhanced by $31.1 \%(P<0.05)$ and $29.1 \%(P<0.05)$ compared with treatment with galanin alone or insulin alone, respectively (Fig. 3). Moreover, the contents in the galanin and insulin groups were increased by $44.1 \%(P<0.05)$ and $46.3 \%$ $(P<0.05)$ in comparison to the diabetic control group respectively. Whereas the 2DG level was lower in the diabetic group compared with the healthy control group $(P<0.01)$.

\section{Plasma RBP4 concentration}

Compared with injection of either galanin or insulin alone, the coadministration of both reagents significantly attenuated the plasma RBP4 concentration in the myocytes as showed in Fig. $4(F(4,40)=26.4, P<0.0001)$. The plasma RBP4 concentration in the cooperative group compared with the galanin-only or insulin-only groups was decreased by $22.1 \%(P<0.05)$ and $19.3 \%(P<0.05)$, respectively. The RBP4 content decreased by $22.4 \%(P<0.01)$ and $25.1 \%$ $(P<0.01)$ in the galanin-only and insulin-only groups, respectively compared with the diabetic control group. The RBP4 level was higher in the diabetic control group than in the healthy control group $(P<0.01)$.

\section{Glut4 mRNA gene expression levels}

In an RT-PCR study, we found that coadministration of the two hormones elevated the Glut4 mRNA levels $(F(4,40)=16.94, P<0.0001$ Fig. 4$)$. As shown in Fig. 5 , the Glut4 mRNA levels in the galanin-only and insulin-only groups were enhanced by $41.0 \%(P<0.05)$ and $52.5 \%$ $(P<0.01)$ respectively compared with the diabetic control group. Although the coadministrative group compared with the groups treated with galanin or insulin alone exhibited an increase in the Glut4 gene expression levels of only $14.3 \%(P>0.05)$ and $5.7 \%(P>0.05)$ respectively, the expression levels in the diabetic control group were lower than those for the healthy control group $(P<0.01)$.

\section{GLUT4 contents in plasma membranes and total cell membranes}

As shown in Fig. 6, the coadministration of galanin and insulin elevated GLUT4 levels in both total cell membranes

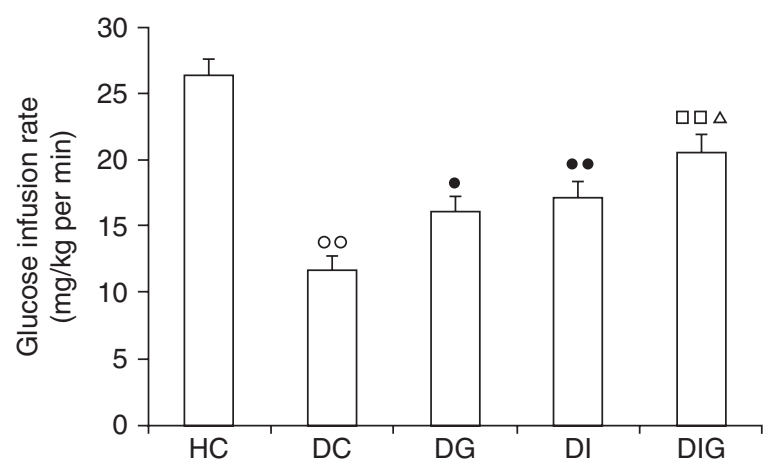

\section{Figure 2}

The coadministration of galanin with insulin increased the glucose infusion rate in the hyperinsulinemic-euglycemic clamp tests in type 2 diabetic rats $(n=8)$. The glucose infusion rates in the coadministrative group (DIG) were higher than those for the diabetic group with galanin (DG) or the diabetic group with insulin (DI). The rates in the DG and DI groups were higher than that for the diabetic control (DC) group. The glucose infusion rate in the DC group was lower than that for the healthy control $(\mathrm{HC})$ group. All data shown are the means \pm S.E.M. ${ }^{\circ} P<0.01$ vs HC; $\bullet P<0.05, \bullet \bullet<0.01$ vs DC; $\square \square P<0.01$ vs DG; $\triangle P<0.05$ vs DI. http://joe.endocrinology-journals.org DOI: $10.1530 / \mathrm{JOE}-13-0444$
() 2014 Society for Endocrinology Printed in Great Britain 


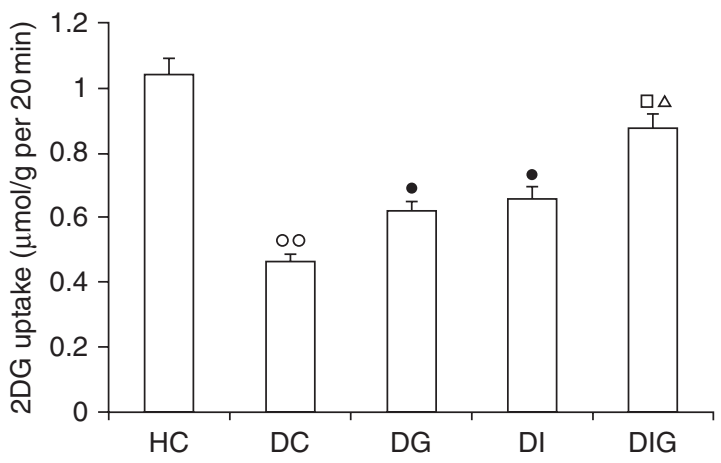

Figure 3

Cotreatment with galanin and insulin elevated the 2-deoxy- $\left[{ }^{3} \mathrm{H}\right] \mathrm{D}$-glucose (2DG) contents in the myocytes of type 2 diabetic rats $(n=8)$. The 2DG uptake was augmented in the coadministrative group (DIG) compared with either the diabetic galanin group (DG) or the diabetic insulin group (DI). Additionally, the 2DG quantities in the DG and DI groups were higher compared with the diabetic control (DC) group. The 2DG content in myocytes of the $D C$ group was lower than that in those of the healthy control $(\mathrm{HC})$ group. The data shown are the means \pm s.E.M. ${ }^{\circ}{ }^{\circ} P<0.01$ vs HC; $\bullet^{P}<0.05$ vs DC; ${ }^{\square} P<0.05$ vs DG; ${ }^{\triangle} P<0.05$ vs DI.

$(F(4,40)=17.1, \quad P<0.0001)$ and plasma membranes $(F(4,40)=21.9, P<0.0001)$ of myocytes. In comparison to injection of galanin or insulin alone, the cooperative injection increased the GLUT4 immunoreactivities in plasma membranes by $34.7 \%(P<0.05)$ and $36.7 \%(P<0.05)$, respectively, but in total cell membranes the increase was non-significant, $4.5 \%(P>0.05)$ and $4.0 \%(P>0.05)$, respectively. The GLUT4 expression levels in plasma membranes of the galanin only and insulin-only groups were significantly elevated by $80.9 \%(P<0.01)$ and $78.3 \%(P<0.01)$, respectively and in total cell membranes they were elevated by $80.9 \% \quad(P<0.01)$ and $78.3 \% \quad(P<0.01)$, respectively, compared with the diabetic control group. While the GLUT4 contents in both membranes of the diabetic control group were lower than the corresponding values for the healthy control group $(P<0.01)$. The ratios of GLUT4 densities in plasma membranes of the total cell membranes were $28.0,16.3,24.1,23.0$, and $30.8 \%$ in the healthy control, diabetic control, diabetic with galanin, diabetic with insulin, and coadministrative groups respectively.

\section{The PAS160 and PKC activity levels in myocytes}

Since direct measurement of PKC isoenzyme-specific activity was not reliable, the total PKC activity was indirectly measured by detecting the changes in the phosphorylation status of various isoenzyme-specific substrates at $1 \mathrm{~min}$. As shown in Fig. 7, cotreatment with galanin and insulin significantly elevated pAS160
$(F(4,40)=23.9, P<0.0001)$ and PKC activity $(F(4,40)=$ $21.4, P<0.0001)$ levels in the myocytes compared with the diabetic galanin and diabetic insulin groups. The pAS160 and PKC activity levels in the coadministrative group were enhanced by $37.2 \%(P<0.01)$ and $25.9 \%(P<0.05), 21.2 \%$ $(P<0.05)$ and $28.5 \%(P<0.01)$ compared with the diabetic galanin and diabetic insulin groups respectively. Both indicies in the galanin-only and insulin-only groups were enhanced by $34.6 \%(P<0.05)$ and $46.7 \%(P<0.01), 38.8 \%$ $(P<0.01)$ and $30.9 \%(P<0.05)$ compared with the diabetic control, whereas the two indicies in the diabetic control group were reduced by $50.5 \%(P<0.01)$ and $43.9 \%$ $(P<0.01)$ compared with the healthy controls.

\section{Discussion}

Much evidence supports the hypothesis that chronically elevated galanin may increase body weight of animals through reduction of energy expenditure and insulin resistance. Homozygous galanin-transgenic mice had increased body weight (Poritsanos et al. 2009). Infusion of galanin caused a rapid, short, and dose-dependent increase in the blood glucose level (Manabe et al. 2003) with elevated sympathetic outflow (Taborsky et al. 1999, Kyrkouli et al. 2006), although administration of galanin for a long period may reduce the blood glucose level via facilitating GLUT4 translocation and reducing insulin resistance (Zhang et al. 2012). In addition, it has been reported previously that galanin may inhibit insulin release by inhibiting adenylate cyclase activity through activation

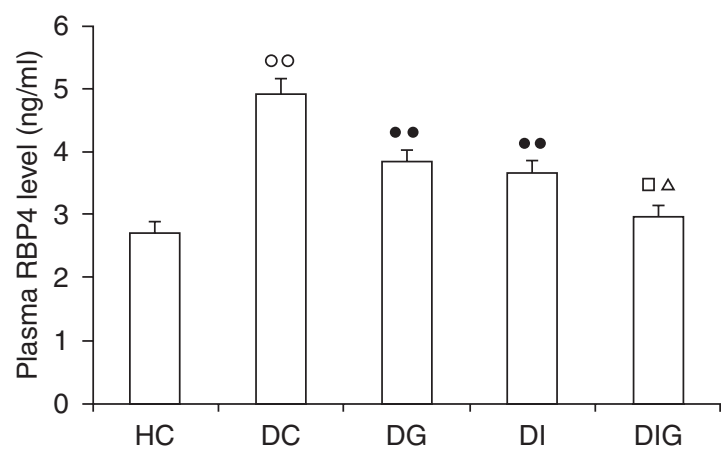

Figure 4

The coadministration of galanin and insulin attenuated the retinol-binding protein 4 (RBP4) contents in the plasma of type 2 diabetic rats $(n=8)$. The RBP4 levels were lower in the cooperative reagent group (DIG) compared with either the diabetic group treated with galanin (DG) or the diabetic group treated with insulin (DI). In addition, the RBP4 levels in the DG and DI groups were lower compared with the diabetic control (DC) group. The RBP4 level in the DC group was higher than that in the healthy control $(\mathrm{HC})$ group. The data shown are the means \pm s.E.M. ${ }^{\circ}{ }^{\circ} P<0.01$ vs HC; $\bullet \bullet P<0.01$ vs DC; ${ }^{\square} P<0.05$ vs DG; ${ }^{\triangle} P<0.05$ vs DI.

Published by Bioscientifica Ltd. 


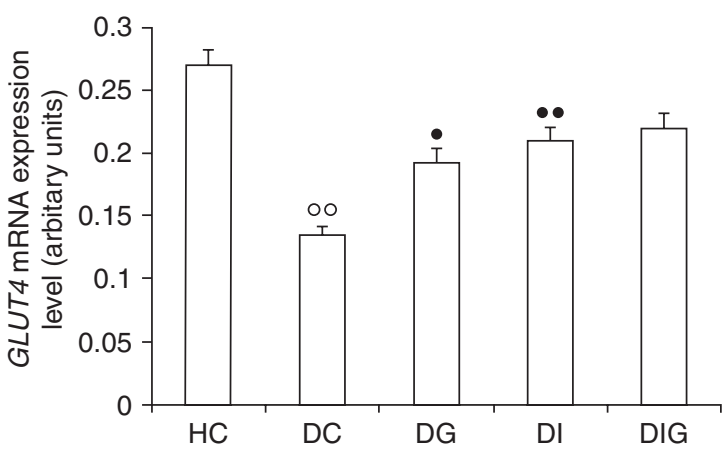

Figure 5

The effect of coadministration of galanin with insulin on the Glut4 mRNA expression levels $(n=8)$. The Glut4 mRNA expression levels in the coadministrative group (DIG) were almost equal to those for the diabetic group with galanin (DG) and the diabetic group with insulin (DI). While the GLUT4 mRNA expression levels in the DG and DI groups were higher than those in the diabetic control (DC) group. The Glut4 mRNA expression level in the DC group was lower than that in the healthy control $(\mathrm{HC})$ group. The data shown are the means \pm s.E.M. ${ }^{\circ}{ }^{\circ} P<0.01$ vs HC; $\bullet_{P<0.05,}^{\bullet} \bullet P<0.01$ vs DC.

of petussis-toxin-sensitive inhibitory GTP-binding regulatory protein (Cheng et al. 2003, Manabe et al. 2003). In the galanin-knockout mice, the initial short inhibition of insulin secretion was impaired, followed by an augmentation of insulin secretion when sympathetic and parasympathetic branches were chemically activated (Ahrén et al. 2004). Furthermore, it is well known that insulin may induce weight gain (Evans 1972), reduce blood glucose levels, and inhibit its own secretion in animals (Wasada et al. 1995). However, to date little is known about the effect of galanin in combination with insulin on body weight, blood glucose, and insulin levels of subjects. In the present study, it was found that cotreatment with galanin and insulin resulted in further amelioration of glycemia and insulinemia in comparison with treatment with galanin or insulin alone in diabetic rats, but the body weight of animals was almost unchanged.

The hyperinsulinemic-euglycemic clamp test is a direct method to assess insulin sensitivity of subjects. An elevated glucose infusion rate in the clamp test indicates a development of insulin sensitivity (Liang et al. 2012). The 2DG taken into cells is phosphorylated to 2DG-6phosphate, which cannot be further metabolized through subsequent steps of glycolysis. Thus, the ${ }^{3} \mathrm{H}-2 \mathrm{DG}$ level in the myocytes becomes a surrogate for glucose transport. The current study revealed that coadministration of galanin with insulin improved glucose infusion rates and ${ }^{3} \mathrm{H}-2 \mathrm{DG}$ contents in euglycemic clamp and 2DG tests vs the same dose of either reagent in myocytes. These results indicate that the combination of the two hormones may exert a synergic effect to improve insulin sensitivity and glucose uptake in myocytes of T2DM rats.

RBP4, composed of 181 amino acids, is a member of the RBP family. The serum RBP4 levels are elevated in insulin-resistant mice and humans with obesity and/or T2DM via impaired insulin signaling (Yang et al. 2005). In obese subjects, there is a positive correlation between plasma RBP4 levels and insulin resistance. Transgenic overexpression of $R b p 4$ or injection of recombinant $R b p 4$ into normal mice may induce insulin resistance (Yang et al. 2005). In contrast, the Rbp4 knockout mice displayed increased insulin sensitivity. Thus, plasma Rbp4 levels may be used as a clinical indicator of insulin resistance and an early prediction of obesity risk (Tajtakova et al. 2010). The present results indicated that the plasma Rbp4 levels were increased in diabetic rats, but were decreased by administration of either insulin or galanin, and further reduced by coinjection of both reagents. These results indicated that insulin resistance may be ameliorated by either insulin or galanin, and coadministration of both hormones may result in a synergic efficiency to further reduce insulin resistance.

Several lines of evidence have indicated that the GLUT4 translocation from intracellular storage organelles

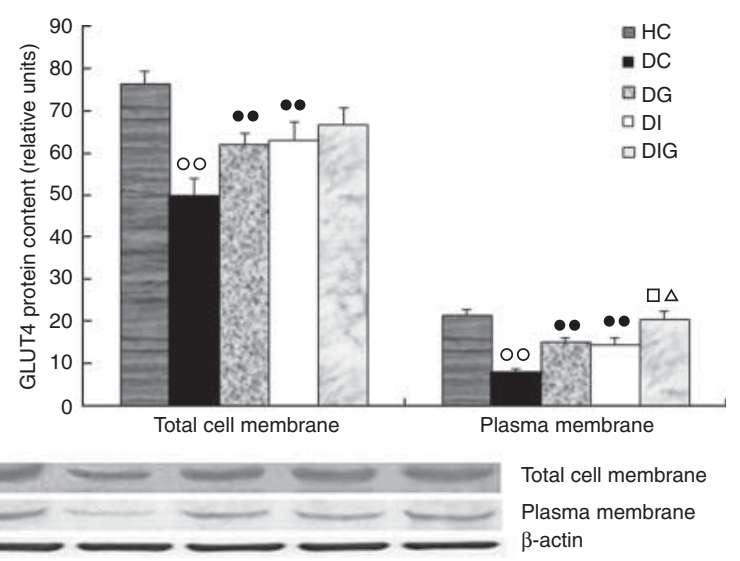

Figure 6

Cotreatment with galanin and insulin increased GLUT4 trafficking to plasma membranes of myocytes in diabetic rats $(n=8)$. The immunoreactivity in plasma membranes was enhanced, but not that in total cell membranes of myocytes in the coadministrative group (DIG) compared with the diabetic group treated with galanin (DG) and the diabetic group treated with insulin (DI) respectively. The immunoreactivity in DG and DI was elevated in both total cell membranes and plasma membranes compared with the diabetic control group (DC). While the GLUT4 expression levels in both sets of membranes in the DC group were lower than the corresponding values for the healthy control (HC) group. The band sequence of the representative western blot for each panel is HC, DC, DG, DI and DIG. The data shown are the means \pm S.E.M. ${ }^{\circ} P<0.01$ vs HC for each type of membrane; $\bullet \bullet P<0.01$ vs DC for each set of membranes, $\square P<0.05$ vs DG for each set of membranes; ${ }^{\triangle} P<0.05$ vs DI for each set of membranes. 


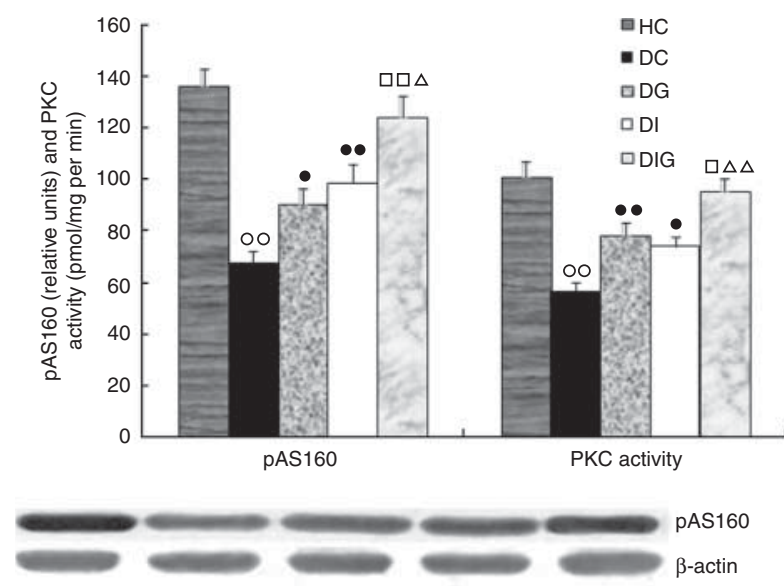

Figure 7

Cotreatment with galanin and insulin enhanced pAS160 and PKC activity levels more than treatment with galanin or insulin alone $(n=8)$. The pAS160 concentration and PKC activity level were higher in the coadministrative group (DIG) than in either the galanin group (DG) or the insulin group (DI). Additionally, the pAS160 and PKC activity levels in the DG and DI groups were higher than those in the diabetic control (DC) group. The levels for both proteins in myocytes of the DC group were lower than those for the healthy control $(\mathrm{HC})$ group. The band sequence of the representative western blot is $\mathrm{HC}, \mathrm{DC}, \mathrm{DG}, \mathrm{DI}$ and DIG. All data shown are the means \pm s.E.M. ${ }^{\circ} \circ P<0.01$ vs HC; $\bullet P<0.05, \bullet \bullet P<0.01$ vs DC; $\square P<0.05$, $\square \square P<0.01$ vs DG; ${ }^{P} P<0.05, \triangle \triangle P<0.01$ vs DI.

to plasma membranes of myocytes is crucial for regulating glucose uptake and insulin sensitivity (Liang et al. 2012). The maximal glucose clearance activity by skeletal muscle is directly proportional to the GLUT4 concentration in plasma membranes (Geiger et al. 2006). The greater the amount of GLUT4 protein at the cell surface, the higher the insulin sensitivity observed (Zhang et al. 2012). Targeted disruption of GLUT4 selectively in muscles resulted in a profound reduction in basal glucose transport and insulin sensitivity of mice (Zisman et al. 2000), whereas overexpression of GLUT4 reversed the reduced glucose uptake in muscle and restored peripheral insulin sensitivity in GLUT4 knockout mice (Ranalletta et al. 2007). The present study provided evidence in vivo that coadiministration of insulin with galanin compared with injection of each alone significantly increased GLUT4 contents in plasma membranes, but not in total membranes and Glut4 mRNA expression levels of myocytes. The ratios of GLUT4 contents in plasma membranes to those in total cell membranes were higher in the coadiministrative group than the single-drug-treated groups. These results indicate that cotreatment with both reagents may promote GLUT4 translocation from intracellular membrane compartments to the plasma membranes of myocytes, but the GLUT4 synthesis speed in the coadministrative group is almost as same as that in the insulin- or galanin-treatment groups.

In animals and humans, efficient signaling of both insulin and galanin is essential and pivotal for maintaining glucose homeostasis and insulin sensitivity. Now there are clues about the synergic effect of insulin and galanin in enhancing insulin sensitivity.

First, it is well documented that galanin receptors are widely distributed within the insulin-sensitive tissues, including muscle, adipose tissue, and heart, which are crucial for maintaining energy homeostasis and insulin sensitivity in subjects (Lang et al. 2007). Next, insulin and galanin coexist in the pancreatic islets (Adeghate \& Ponery 2001). The similar distribution of the two hormone receptors offers a morphological basis for their synergic effect in elevating insulin sensitivity. Furthermore, there is a crosstalk between insulin and galanin in their synthesis and secretion. Daily administration of insulin increased galanin-like immunoreactivity in the myenteric plexus of the ileum in 12-week-old rats as rigorous control of their glycemia (Belai et al. 1996). The splanchnic nerve stimulation induced by insulin resulted in a rapid and robust upregulation of galanin biosynthesis in the chromaffin cells (Anouar \& Eiden 1995). After administration of insulin, the galanin mRNA levels in adrenals were maximally increased at $4 \mathrm{~h}$, remained at maximal elevation for at least $48 \mathrm{~h}$, and returned to baseline levels in 6 days (Anouar \& Eiden 1995). Whereas an infusion of galanin, as mentioned above, caused a rapid, reversible, and dose-dependent reduction in basal insulin secretion from pancreatic islets via pertussis-toxinsensitive G proteins (Cheng et al. 2003, Manabe et al. 2003). Interestingly, the injection of galanin has an inhibitory effect on glucose-stimulated, but not L-arginineor potassium-stimulated, insulin release in animals (Yoshimura et al. 1989) but fails to modify insulin secretion in man (Ghigo et al. 1992). Lastly, the synergy between insulin and galanin may result from the superimposed efficiency of their signaling cascades. The canonical insulin-signaling pathway to trigger GLUT4 translocation is composed of PKC, Akt substrate of $160 \mathrm{kDa}$ (AS160) and so on (Sakamoto \& Holman 2008, Stretton et al. 2010). While galanin-induced GLUT4 trafficking is activated at least via two discrete signaling pathways involving its three subtypes, GalR1-3. The first pathway activates GalR1 and GalR3 to decrease the activity of the cAMP response element binding proteins through Gi/o proteins, resulting in the activation of AS160 (Lang et al. 2007). The second pathway activates GalR2 via $\mathrm{Gq} / 11$, generating the hydrolysis of inositol phosphate

Published by Bioscientifica Ltd. 
and activation of PKC. Thus, both signaling pathways of insulin and galanin involve the same signaling proteins, AS160 and PKC, which become the meeting points and intersections of the two signaling pathways to trigger GLUT4 traffic. In this study, we found that the pAS160 and PKC activity levels in the cotreatment group were higher than those observed in the groups treated with galanin alone or insulin alone indicating that the interaction and interplay between the two signaling cascades may amplify their intensity and enhance their efficacy of transmission, as a consequence inflating their gains in GLUT4 translocation and glucose uptake in the myocytes of T2DM rats.

In short, compared with administration of insulin or galanin, the synergic effect of the two hormones efficaciously improved GLUT4 translocation and insulin sensitivity in the myocytes of T2DM rats. This indicates that galanin in combination with insulin may achieve better curative efficacy than the canonical treatment with insulin alone for insulin resistance and T2DM. This should be helpful for developing new therapeutic strategies for T2DM.

\section{Declaration of interest}

The authors declare that there is no conflict of interest that could be perceived as prejudicing the impartiality of the research reported.

\section{Funding}

This work was supported by the Grant of the National Natural Scientific Fund of China (81001572 and 81070238).

\section{Author contribution statement}

$L B$ and $S Q$ designed the study and played a key role in the interpretation of data analysis and drafting the manuscript. Q Y, Z L, W T, and J Z played a key role in data collection, editing the manuscript and approval of the submitted version.

\section{References}

Adeghate E \& Ponery AS 2001 Large reduction in the number of galanin-immunoreactive cells in pancreatic islets of diabetic rats. Neuroendocrinology 13 706-710. (doi:10.1046/j.1365-2826.2001. 00682.x)

Ahrén B, Pacini G, Wynick D, Wierup N \& Sundler F 2004 Loss-of-function mutation of the galanin gene is associated with perturbed islet function in mice. Endocrinology 145 3190-3796. (doi:10.1210/en.2003-1700)

Anouar Y \& Eiden LE 1995 Rapid and long-lasting increase in galanin mRNA levels in rat adrenal medulla following insulin-induced reflex splanchnic nerve stimulation. Neuroendocrinology 62 611-618. (doi:10.1159/000127057)

Atalik KE, Okudan N, Gokbel H, Kalkan S \& Cuce G 2010 Diabetes mellitusand cooling-induced bladder contraction: an in vitro study. Journal of Smooth Muscle Research 46 175-183. (doi:10.1540/jsmr.46.175)

http://joe.endocrinology-journals.org DOI: $10.1530 / \mathrm{JOE}-13-0444$
() 2014 Society for Endocrinology Printed in Great Britain
Belai A, Calcutt NA, Carrington AL, Diemel LT, Tomlinson DR \& Burnstock G 1996 Enteric neuropeptides in streptozotocin-diabetic rats; effects of insulin and aldose reductase inhibition. Journal of the Autonomic Nervous System 58 163-169. (doi:10.1016/01651838(95)00129-8)

Cheng H, Straub SG \& Sharp GW 2003 Protein acylation in the inhibition of insulin secretion by norepinephrine, somatostatin, galanin and $\mathrm{PGE}_{2}$. American Journal of Physiology. Endocrinology and Metabolism 285 E287-E294. (doi:10.1152/ajpendo.00535.2002)

Evans AJ 1972 The effect of protamine zinc insulin on weight gain and fat deposition in the juvenile domestic duck. Quarterly Journal of Experimental Physiology and Cognate Medical Sciences 57 1-11.

Geiger PC, Han DH, Wright DC \& Holloszy JO 2006 How muscle insulin sensitivity is regulated: testing of a hypothesis. American Journal of Physiology. Endocrinology and Metabolism 291 E1258-E1263. (doi:10.1152/ajpendo.00273.2006)

Ghigo E, Maccario M, Arvat E, Valetto MR, Valente F, Nicolosi M, Mazza E, Martina V, Cocchi D \& Camanni F 1992 Interactions of galanin and arginine on growth hormone, prolactin, and insulin secretion in man. Metabolism 41 85-89. (doi:10.1016/0026-0495(92)90195-G)

Guo L, Shi M, Zhang L, Li G, Zhang L, Shao H, Li J, Fang P, Ma Y, Shi Q et al. 2011 Galanin antagonist increases insulin resistance by reducing glucose transporter 4 effect in adipocytes of rats. General and Comparative Endocrinology 173 159-163. (doi:10.1016/j.ygcen.2011.05.011)

He B, Shi M, Zhang L, Li G, Zhang L, Shao H, Li J, Fang P, Ma Y, Shi Q et al. 2011 Beneficial effect of galanin on insulin sensitivity in muscle of type 2 diabetic rats. Physiology \& Behavior 103 284-289. (doi:10.1016/ j.physbeh.2011.02.023)

Jiang L, Shi M, Guo L, He B, Li G, Zhang L, Zhang L \& Shao H 2009 Effect of M35, a neuropeptide galanin antagonist on glucose uptake translated by glucose transporter 4 in trained rat skeletal muscle. Neuroscience Letters 467 178-181. (doi:10.1016/j.neulet.2009.10.034)

Kyrkouli SE, Strubbe JH \& Scheurink AJ 2006 Galanin in the PVN increases nutrient intake and changes peripheral hormone levels in the rat. Physiology \& Behavior 89 103-109. (doi:10.1016/j.physbeh.2006. 05.009)

Lang R, Gundlach AL \& Kofler B 2007 The galanin peptide family: receptor pharmacology, pleiotropic biological actions, and implications in health and disease. Pharmacology \& Therapeutics 115 177-207. (doi:10.1016/j.pharmthera.2007.05.009)

Legakis IN 2005 The role of galanin in metabolic disorders leading to type 2 diabetes mellitus. Drug News \& Perspectives 18 173-177. (doi:10.1358/ dnp.2005.18.3.892762)

Legakis IN, Mantzouridis T \& Mountokalakis T 2007 Positive correlation of galanin with glucose in healthy volunteers during an oral glucose tolerance test. Hormone and Metabolic Research 39 53-55. (doi:10.1055/ s-2006-957346)

Li RY, Song HD, Shi WJ, Hu SM, Yang YS, Tang JF, Chen MD \& Chen JL 2004 Galanin inhibits leptin expression and secretion in rat adipose tissue and 3T3-L1 adipocytes. Journal of Molecular Endocrinology 33 11-19. (doi:10.1677/jme.0.0330011)

Liang Y, Sheng S, Fang P, Ma Y, Li J, Shi Q, Sui Y \& Shi M 2012 Exercise-induced galanin release facilitated GLUT4 translocation in adipocytes of type 2 diabetic rats. Pharmacology Biochemistry and Behavior 100 554-559. (doi:10.1016/j.pbb.2011.10.026)

Manabe T, Okada Y, Sawai H, Funahashi H, Yamamoto M, Hayakawa T \& Yoshimura T 2003 Effect of galanin on plasma glucose, insulin and pancreatic glucagon in dogs. Journal of International Medical Research $\mathbf{3 1}$ 126-132. (doi:10.1177/147323000303100209)

Poritsanos NJ, Mizuno TM, Lautatzis ME \& Vrontakis M 2009 Chronic increase of circulating galanin levels induces obesity and marked alterations in lipid metabolism similar to metabolic syndrome. International Journal of Obesity 33 1381-1389. (doi:10.1038/ ijo.2009.187)

Ranalletta M, Du XQ, Seki Y, Glenn AS, Kruse M, Fiallo A, Estrada I, Tsao TS, Stenbit AE, Katz EB et al. 2007 Hepatic response to restoration of GLUT4

Published by Bioscientifica Ltd 
in skeletal muscle of GLUT4 null mice. American Journal of Physiology. Endocrinology and Metabolism 293 E1178-E1187. (doi:10.1152/ajpendo. 00628.2006)

Sakamoto K \& Holman GD 2008 Emerging role for AS160/TBC1D4 and TBC1D1 in the regulation of GLUT4 traffic. American Journal of Physiology. Endocrinology and Metabolism 295 E29-E37. (doi:10.1152/ ajpendo.90331.2008)

Stretton C, Evans A \& Hundal HS 2010 Cellular depletion of atypical PKC $\lambda$ is associated with enhanced insulin sensitivity and glucose uptake in L6 rat skeletal muscle cells. American Journal of Physiology. Endocrinology and Metabolism 299 E402-E412. (doi:10.1152/ajpendo.00171.2010)

Taborsky GJ Jr, Dunning BE, Havel PJ, Ahren B, Kowalyk S, Boyle MR, Verchere CB, Baskin DG \& Mundinger TO 1999 The canine sympathetic neuropeptide galanin: a neurotransmitter in pancreas, aneuromodulator in liver. Hormone and Metabolic Research 31 351-354. (doi:10.1055/s-2007-978752)

Tajtakova M, Petrasova D, Pidanicova A, Gallovicova A, Blanarova C \& Petrovicova J 2010 Serum levels of leptin, adiponectin, retinol binding protein 4 and leptin/adiponectin molar ratio as another possible marker of insulin resistance in obese. Bratislavské Lekárske Listy $111212-215$
Wasada T, Aoki K, Babazono T, Kuroki H, Arii H, Saeki A \& Omori Y 1995 Insulin sensitivity and negative insulin feedback after pancreas transplantation in insulin-dependent diabetic patients. Endocrine Journal 42 747-752. (doi:10.1507/endocrj.42.747)

Yang Q, Graham TE, Mody N, Preitner F, Peroni OD, Zabolotny JM, Kotani K, Quadro L \& Kahn BB 2005 Serum retinol binding protein 4 contributes to insulin resistance in obesity and type 2 diabetes. Nature 436 356-362. (doi:10.1038/nature03711)

Yoshimura T, Ishizuka J, Greeley GH Jr \& Thompson JC 1989 Effect of galanin on glucose-, arginine-, or potassium-stimulated insulin release. American Journal of Physiology 256 E619-E623.

Zhang Z, Sheng S, Guo L, Li G, Zhang L, Zhang L, Shi M, Bo P \& Zhu Y 2012 Intracerebroventricular administration of galanin antagonist sustains insulin resistance in adipocytes of type 2 diabetic trained rats. Molecular and Cellular Endocrinology 361 213-218. (doi:10.1016/j.mce. 2012.04.012)

Zisman A, Peroni OD, Abel ED, Michael MD, Mauvais-Jarvis F, Lowell BB, Wojtaszewski JF, Hirshman MF, Virkamaki A, Goodyear LJ et al. 2000 Targeted disruption of the glucose transporter 4 selectively in muscle causes insulin resistance and glucose intolerance. Nature Medicine 6 924-928. (doi:10.1038/78693)

Received in final form 21 January 2014

Accepted 5 February 2014

Accepted Preprint published online 5 February 2014
() 2014 Society for Endocrinology Printed in Great Britain
Published by Bioscientifica Ltd. 